\title{
Validation of Antecedents of ERP Success in Indian Higher Educational Institutes
}

\author{
Pratima N. Dabholkar \\ National Institute of Industrial Engineering (NITIE), \\ India
}

\begin{abstract}
Educational institutes are started adopting Enterprise Resource Planning (ERP) systems to manage their resources. Despite such huge amounts being spent on ERPs, recent industry reports and academic studies have indicated that many adopting Higher Educational Institutes (HEI) have come to realize that the deployments of such systems were not as effective as expected. In spite of implementation of ERP in HEI, ERP usage is very limited. The main objective of the study was to identify the factors influencing ERP usage in Indian higher educational institutes. The conceptual framework of this study is based on DeLone \& McLean ERP success model. Organizational factors are integrated with the technological factors of the DeLone and McLean ERP Success model for the study and was tested empirically using questionnaire as a survey instrument. Primary data was collected from 205 Indian higher educational institutes of pan India. Total 346 respondents participated in the study. Technological factor "ease of use" and organizational factor "top management support" are found to be most reliable measures for measuring ERP success in higher educational institutes. Other technological and organizational factors are also found to be suitable for measuring ERP success in higher educational institutes. Identification of factors for measuring ERP success in Indian higher educational institutes is the unique contribution of this study.
\end{abstract}

\section{General Terms}

ERP Success evaluation

\section{Keywords}

Enterprise Resource Planning, Organizational Factors, Technological Factors, ERP Usage, ERP Success

\section{INTRODUCTION}

The opportunity to make profits from Information and Communication Technologies (ICT) was predominantly perceived by manufacturing enterprises. These opportunities were later comprehended by the state and its institutions. Higher Education sector is adopting ICT not only from the perspective of re-designing education and research activities, but to overcome the limitations of the traditional systems and also to support business functions. Presently, not even 2 per cent of the Indian institutes are automated and less than 0.5 per cent Indian Institutes have implemented an ERP solution. The Indian ERP market is projected to be worth Rs. 40,0000 million and is expected to grow at a CAGR of 25 percent in the next 3-4 years. A very high failure rate of ERP, almost 93\% (approximately) makes it a very serious issue which necessities an immediate attention [1]. The higher educational

\author{
Hema Date \\ National Institute of Industrial Engineering (NITIE), \\ India
}

institutes in India is going through a transformation, but as compared to other industries the changes in the HE system is really slow. Lack of resources, resistance to new system, poor communication between different stakeholders of the higher education institutes, huge and distributed file systems, difficulty in generating time table, allocation of courses, scheduling of the classes, maintaining attendance, lack of transparency in the system, huge manual work, keeping records in paper form, difficulty in tracking old records, duplication of work as there is no centralized database and many other complex reasons are accountable for this slow growth in higher education environment. Figure-1 below shows the prevalence of difficulties with Enterprise Resource Planning implementation in public sector. Educational institutes have started implementing ERP systems to enhance their academic processes as well as to make them more flexible and transparent $[2,3,4,5]$. Many educational institutes are ready to invest in ERP as it is still in its emerging state and will have a potential growth rate in forth coming years [6]. By looking at the need and importance of ERP in educational sector, ERP vendors are started entering into the untapped market such as educational sector [7]. Many institutes have made significant investment in ERP while the implementation was quite successful, a considerable number of them were unable to achieve the expected objectives [8]. ERP implementation is said to be successful only when the organization started using the ERP system in their day to day activities and achieving business benefits in post implementation stage [9].

HEIs invest considerably in ERP systems but finding it tough to identify the expected benefits after the usage in terms of individual performance which should be redirected in the organizational performance and services they provide to the different stakeholders [2]. Therefore, stringent evaluation to capture ERP technology, organizational issues and measurement of ERP success is desirable [10]. According to studies $70 \%$ of ERP implementations fail to deliver expected benefits [11]. So, if ERP system is such a high risk project to be implemented and use, there is a necessity to evaluate the ERP system success on different parameters [12]. Numerous studies have been conducted to study ERP adoption and the impact of ERP on individual and at organizational level. The critical success factors of ERP systems has been widely researched in an organizational context $[13,14,15,16]$ however, few have investigated the post implementation of ERP success in institutional context $[10,2,17,18,19,20]$. Paucity of research on ERP systems after its implementation and the dearth of research on measurement of ERP success in HE environment motivates this research $[6,21]$. 


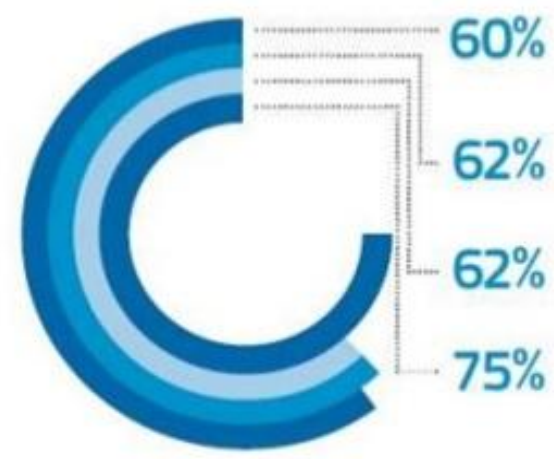

$60 \%$ of Organizations reported that

functionality of their ERP system fall short

of expectations

$62 \%$ reported adoption and ease of use fell short of expectations.

$62 \%$ reported disappointment with the systems level of customization.

$75 \%$ reported that overall implementation

experience will or did fall short of expectation.

Figure-1 Statistics from GFOA's "Real Impact of ERP Systems in Public Sector" and NASACT's 2012 "Challenge of Change"

\section{LITERATURE REVIEW}

ERP implementation in the institute improves transparency, communication, tracking and forecasting. On the other side universities are less confident about streamlining of academic processes, work flow and improved customer service and satisfaction. ERP being expensive is not perceived as a major limitation. Major problems faced by the universities during ERP implementations are active participation from all the people from the university and providing training to the user. Therefore, the user perceived that ERP software developed is not exactly as per need of the organization, in-depth study has not been done by the vendor and software is not customized in a timely manner [8]. Many researchers have attempted to examine the implementation of ERP in the domain of Education sector and have identified Critical Success Factors (CSF) that affect an implementation of ERP in an educational institution. Most significant CSF identified from the literature are Top Management Support, Change Management, Training and Education [22, 23, 5].

\subsection{ERP Success Measurement Model}

Delone and Mclean (1992) proposed, but did not empirically test, a model of IS success that included six constructs: system quality, information quality, use, user satisfaction, individual impact and organizational impact. Delone and McLean updated model [13] included service quality as a construct. They replaced the variables, individual impact and organizational impact with net benefit, thereby accounting for benefits at multiple levels of analysis which is not restricted to individual impact and organizational impact. Sedera et al. [16] study provided the most complete and comprehensive success measurement study and it is the first validated instrument to gauge enterprise system success. Study suggested the existence of four distinct and individually important dimensions of success that the authors believe are applicable to any IS evaluation. These four dimensions are system quality, information quality, individual impact and organizational impact. The constructs are positively associated and when combined yield a single valid measure of overall success.

Wixom and Todd [24] suggested a model which integrated the Technology Acceptance Model (TAM) and user satisfaction model as two models represent complementary steps in a causal chain from key characteristics of system design to beliefs and expectations about outcomes that ultimately determine usage. Sabherwal et al. [15] study explains the interrelationships among four constructs representing the success of a specific IS (user satisfaction, system use, perceived usefulness, and system quality), and the relationships of these IS success constructs with four userrelated constructs (user experience with ISs, user training in ISs, user attitude toward ISs, and user participation in the development of specific ISs). Ifinedo [25] developed ERP system success measurement model to investigate the impacts of size, culture, and structure of the adopting organization on ERP system success. Author also considered the effects of organizational IT issues or factors such as IT assets and resources (i.e. the IT department's value, the IT department's size, and the sophistication of the in-house IT professionals, among others) on ERP systems success.

Chung [26] success model is based on technology acceptance model and DeLone and McLean's information systems success model integrated with key project management principles. Ifinedo [27] noted that research on the impacts of organizational culture and information technology (IT) resources on ERP system success are rare. With regard to his study, the ERP system success construct, which is designed to measure the performance or benefits of the implemented system to the organization, is the main or dependent construct while organizational culture and IT resources represent the contingency factors. Abdel [28] study modified the dimension of the TAM and D\&M IS Success Models and added two additional success dimensions i.e. Management support and training. An integrated model for evaluating IS success was generated; the proposed model has been validated by an empirical study based on a questionnaire and interview. Rajan [29] proposed a conceptual framework and examined it to find the effect of some of the individual, organizational, and technological factors on the usage of ERP and its impact on the end user. Table-1 below indicate the list of measures/factors used by the researchers to measure ERP success.

From the literature it has been found that DeLone \& McLean [13] model is the basis of the ERP success measurement and it has been widely used by the researchers. Much like business, higher education institutions are also being driven to become more efficient, provide better services to the customers are faced with increased competition, and must do all of this with reduced funding. Before implementation of ERP in Universities, management need to understand that ERP software available in the market and implemented in business environment cannot be used as it is in the universities. This is ERP-Post-implementation study where ERP system is already in place. ERP post implementation period more than 2 years was considered for study. In this case, it is assumed that users have already adopted the system and it is in use for day-to-day 
processes. Implemented system is in ERP handshake phase. Therefore adoption factors are not considered for the study.
ERP success depends, if the system is extensively used and optimized fully for day-to-day operation.

Table-1 ERP Success Measures

\begin{tabular}{|c|c|c|c|}
\hline No & Author/Year & Research Study & Description of Measures \\
\hline 1. & $\begin{array}{l}\text { Goodhue \& } \\
\text { Thompson } \\
\text { (1995) }\end{array}$ & Task Technology Fit model & $\begin{array}{l}\text { Task characteristics, technology characteristics, individual } \\
\text { characteristics, precursors of utilization, task technology fit, } \\
\text { utilization, performance impacts }\end{array}$ \\
\hline 2. & Seddon (1997) & Information system success & $\begin{array}{l}\text { System quality, information quality, perceived usefulness, user } \\
\text { satisfaction, benefit to individual, benefit to organizational, benefit } \\
\text { to society }\end{array}$ \\
\hline 3. & $\begin{array}{l}\text { DeLone and } \\
\text { McLean (2003) }\end{array}$ & Information system success & System quality, information quality, service quality, net benefit \\
\hline 4. & Sedera (2004) & Enterprise system success & $\begin{array}{l}\text { System quality, information quality, individual impact, } \\
\text { organizational impact }\end{array}$ \\
\hline 5. & $\begin{array}{l}\text { Wixom and } \\
\text { Todd }(2005)\end{array}$ & $\begin{array}{l}\text { Theoretical integration of user } \\
\text { satisfaction and technology } \\
\text { acceptance }\end{array}$ & $\begin{array}{l}\text { Information quality, information satisfaction, usefulness, system } \\
\text { quality, system satisfaction, ease of use, attitude, intention }\end{array}$ \\
\hline 6. & $\begin{array}{l}\text { Sabherwal } \\
(2006)\end{array}$ & $\begin{array}{l}\text { Determinants of Information } \\
\text { System (IS) success. }\end{array}$ & $\begin{array}{l}\text { User satisfaction, system use, perceived usefulness, system quality, } \\
\text { user experience, user training, user attitude, user participation, top- } \\
\text { management support. }\end{array}$ \\
\hline 7. & Ifinedo (2007) & ERP success evaluation & $\begin{array}{l}\text { Vendor/Consultant Quality, System Quality, Information Quality, } \\
\text { Individual Impact, Workgroup Impact, Organizational Impact }\end{array}$ \\
\hline 8. & Ifinedo (2008) & ERP success evaluation & $\begin{array}{l}\text { Top management support, business vision, external expertise, } \\
\text { System Quality, Information Quality, Individual Impact, Workgroup } \\
\text { Impact, Organizational Impact }\end{array}$ \\
\hline 9. & Ifinedo (2010) & ERP success evaluation & $\begin{array}{l}\text { System Quality, Service Quality, Individual Impact, Workgroup } \\
\text { Impact, Organizational Impact, organizational culture, IT resources }\end{array}$ \\
\hline 10. & Ifinedo (2011) & ERP success evaluation & external expertise and in-house or internal computer/IT knowledge \\
\hline 11. & $\begin{array}{l}\text { Tsai, Lee, Liu, } \\
\text { Lin, and Chou } \\
\text { (2012) }\end{array}$ & ERP Success & $\begin{array}{l}\text { ERP system quality, information quality, system use, user } \\
\text { satisfaction, individual impact and organizational impact }\end{array}$ \\
\hline 12. & $\begin{array}{l}\text { Chou J. S. and } \\
\text { Hong (2013) }\end{array}$ & ERP Success & $\begin{array}{l}\text { ERP system quality, information quality, service quality, system use, } \\
\text { user satisfaction, corporate benefit. }\end{array}$ \\
\hline 13. & Ifinedo (2014) & ERP success evaluation & $\begin{array}{l}\text { IT antecedents: assets and resources, System Quality, Information } \\
\text { Quality, Individual Impact, Organizational Impact }\end{array}$ \\
\hline 14. & Hsu (2015) & $\begin{array}{l}\text { Assessing ERP post- } \\
\text { implementation Success }\end{array}$ & System quality, Information quality, Service quality \\
\hline
\end{tabular}

Therefore it is necessary to evaluate the quality of the ERP software to know the comfort of use and organization culture which facilitates ERP usage.

Success dimensions of Delone \& McLean [13] model are interrelated rather than independent. This has important implications for the measurement, analysis, and reporting of IS success empirical studies. In the D\&M IS Success Model, "systems quality" measures technical success; "information quality" measures semantic success. These measures were studied by Seddon [30] in the university environment and found significant relationship between system quality and information quality with ERP success. Quality of the system has three major dimensions: "information quality," "systems quality," and "service quality." Each should be measured or controlled for separately, because singularly or jointly, they will affect subsequent "use" and "user satisfaction." [13].

Higher educational institutes are differing in culture and communication structure. Before implementing ERP in the educational sector, these differences needs to be considered by the educational institutes to acquire benefits after ERP implementation [31]. ERP system can be successfully implemented technically but not from an organizational perspective [22]. The success depends upon the willingness of users to work on the new ERP system [32]. This eventually increases the need to evaluate the ERP usage from both technological and organizational perspective. Success of the information system is required to measure in terms of the overall system quality, the information quality of the ERP system, how the generated information used in the organization, the user satisfaction with the ERP system, the services provided by the ERP system and the impact of ERP systems on user and organization. ERP success will be achieved if organization continue to pay attention to these variables in design and implementations [33]. Followings are the technological and organizational factors considered for measuring ERP success in Indian higher educational environment.

\subsection{Technological Factors (TF) for measuring ERP Success}

\subsubsection{System Quality $(S Q)$}

System quality particularly focus on performance characteristics of the system under study [34]. System quality and information quality alone and together impact ERP usage and user satisfaction [13]. The perceived ease of use is the most common measure of system quality in Technology 
Acceptance Model (TAM). Adaptability, flexibility, availability and reliability and response are the measures of the system quality. System quality is the quality of the system in terms of reliability, ease of use, and response time. System quality is the most necessary characteristics of an information system $[13,15,35]$. To measure system quality three factors which are look and feel, ease of use and flexibility are considered for this study.

\subsubsection{Look and Feel ( $\mathrm{LnF})$}

In software designing, look and feel is a term which used in respect of user interface through which user interact with the system by entering or processing data. This interface comprises various characteristics such as design of each screen, availability of various options, menus, availability of validation alerts, error messages, colors used in the screen, shapes and size, layout, and user friendly look as well as the behavior of dynamic elements such as buttons, boxes, and menus. Look and Feel is one of the important factor in the software to attract people and increase the usability of the software. A common look and feel among the different ERP modules, lowering barriers to staff learning the system. It enable users to easily see how to perform an entire process.

\subsubsection{Ease of Use (EOU)}

The technology acceptance model is based on the theory of reasoned action (TRA) [36] which proposes that an individual's behavioral intention to use a system is determined by two beliefs: perceived usefulness (PU) and perceived ease of use (PEOU) [37,38]. If the ERP system is too cumbersome, employees of the organization will most likely resist using the system. The benefits which are reduce training time and cost, increase user adoption and ensure expected ERP benefits will reap when the ERP interface is intuitive and easy for most employees to use.

\subsubsection{Flexibility $(F X)$}

Flexibility is one of the most desirable quality of system quality which has a capability to follow rules and organization changes [40]. ERP system to remain effective must have great flexibility quality, along with the capability to adapt and upgrade quickly $[39,16,35,24]$.

\subsubsection{Information Quality (IQ)}

Information Quality as the desirable characteristics of the system outputs; that is, management reports and Web pages [35]. Information quality is not measured as a unique construct, but is measured as a factor of user satisfaction. Information quality is an important factor for the adoption of services. In real, every study has interpreted and classified Information Quality criteria conform to its context [34]. Completeness, ease of understanding, relevance and security are the factors identified by Delone \& McLean [13] to measure information quality. Lee [41] study considered availability, usability, format, conciseness, and accessibility to measure information quality of the system [16, 34].

\subsubsection{Service Quality (SERQ)}

Commonly used measures of Information System (IS) effectiveness focus on products, rather than the services, of the IS function [42]. The service quality expected in this study is the required features of the ERP modules in terms of providing services to the organization. Thus there is the danger that IS researchers will mismeasure IS effectiveness if they do not include in their assessment package a measure of IS service quality. Petter et al. [35] mentioned that,
SERVQUAL developed by Parasuraman in 1994 is the often used measure of measuring service quality of IS, it has received some criticism. However, using confirmatory factor analysis, Jiang et al. [43] found that SERVQUAL is indeed a satisfactory instrument for measuring IS service quality. Factors which are considered to measure service quality based on SERVQUAL proposed by Parasuraman et al. [44], are "reliability" and "assurance".

\subsubsection{Reliability (REL)}

Reliability is the likelihood that a system will perform as expected and will do so during its operational life. Each interruption of working process incurs financial and client losses, or even damages the company's reputation. Reliability will ensure the continuity of business operations. Therefore, IT practitioners consider ERP reliability as one of the most important ERP evaluation and selection factor [45]. ERP reliability is the second most important selection criterion, right after ERP functionality [46].

\subsubsection{Assurance (ASSU)}

Assurance is the ability of the ERP software to build users' confidence and provide prompt and assured service at required time. Better and assured service provided by the ERP software will lead to maximum utilization and have better impact on organizational performance.

\subsection{Organizational Factors (OF) for measuring ERP Success}

Three organization factors which facilitate ERP success are considered for the study are Organizational IT Capabilities, Top Management support and Training and Education.

\subsubsection{Organizational IT Capabilities (OIC)}

ERP success is not only dependent on the quality of the software but it is also dependent on the organizational IT capabilities and IT resources of the organization. Organizational IT capabilities and the availability of IT resources are positively related to the success of ERP for adopting firms [27]. Lester [47] mentioned that there is an increasing importance of information technology to organizational survival and success. From word processing, to networking, to the internet, to e-commerce. Investment in IT is includes computers, telecommunications, network equipment and their necessary hardware, software, and services. Organization IT capability has the strong impact on ERP success. In an educational sector in particular all users do not have the same technical competency, IT resources available in the institute are limited. Due to inappropriate IT support ERP performance minimizes. Organization culture and IT resources have strong impact on ERP success. Whereas, IT resources have positive impact on ERP success than organization culture (Ifinedo, 2010). Technology capability has a strong influence on firm's performance. There is lack of standard instrument to measure organization IT capability. This particular variable is not much explored in earlier research [48].

\subsubsection{Skill and sophistication of IT staff (SSITS)}

A department that manages and supports information systems can more effectively support the organization if it is structured in a way that aligns with the overall organization's priorities [49]. ERP systems also necessitate skilled professionals to manage implemented ERP system on a continuous basis. For managing IT infrastructure and IT processes there is a separate division in higher educational institutes. Therefore, 
they plays an important role in ERP success. At post implementation stage continuous support from IT department is required for realizing the benefits of ERP.

\subsubsection{IT Resources (ITR)}

IT resources are hardware and Software available at the institute. Availability of upgraded and ERP compatible software and hardware facilitates the smooth functioning of ERP system. Ein-Dor and Segev [50] noted that "budgeting of sufficient resources increases the likelihood of MIS success" [27]. The poor IT infrastructure will most probably lead to a slow processing capability of the ERP system [51]

\subsubsection{Top Management Support (TMS)}

The success of a major project like an ERP implementation completely hinges on the strong, sustained commitment of top management. This commitment when percolated down through the organizational levels results in an overall organizational commitment [52]. Top management support is cited as the most critical success factor for ERP success. Top management support is required in all phases of ERP implementation [53]. Hsu et al. [54] study explored the effect of top management support to system quality, service quality and user satisfaction. The results confirm the importance of top management involvement for ERP success. Top management support is required to make provision of the resources required for ERP success. Top management should set realistic goal before ERP implementation so that it can be achieved. The benefits of having integrated system should be communicated to all stakeholders by involving them into the project so that resistance for the system can be avoided. Top management should support user inputs related to technology, processes and formulate Information Technology (IT) strategy to align with organization processes. Management should be aware of the capabilities and limitation of the system. So that, unwanted expectation from the system will not discourage the user from using the system.

\subsubsection{Training and Education (TE)}

Sabheral et al. [15] defined user training in ISs as the extent to which an individual has been trained about ISs through courses, training, manuals, and so on. The level of training an organization's employees undergo with respect to information system will have a positive relationship with implementation success [55,2].

\subsubsection{ERP Usage (EU) as a mediating factor influencing ERP success}

Goodhue [14] noted that utilization is the behavior of employing the technology in completing tasks. Increased utilization will lead to positive performance impacts. Utilization measures the frequency and utility of the diverse applications employed. The benefits of ERP is not just obtained due to improved operational efficiency but the required services obtained from the implemented system during ERP post implementation phase and understanding the importance of ERP for the day to day operation during its use [56]. Due to lack of top management involvement, poor selection of ERP software, ERP software not with conformance with the institute need and non-availability of training and education leads to minimum usage of ERP system. Though software implementation is successful, but the ERP usage is minimum, it will not add any value to the organization. Therefore, 'ERP usage' is considered for measuring ERP success for this study. A complete usage of ERP system will give maximum benefit to an organization and add value to individual as well as organization performance. ERP value lies in providing management with data for operational and strategic planning, better decisionmaking, and for improving customer facing processes. Therefore, ERP value is likely to be higher if management can effectively use the information provided by ERP systems for operational and strategic purposes [57].

It can be observed from the above discussion that organizational factors along with the technological factors, combining to measure ERP success in higher educational context has received less attention. Furthermore, in India's context there has been no follow up studies to evaluate the success of ERP implementation and understanding the reasons for its success and failure. Therefore for this study technological and organizational factors are combined together to measure ERP success in higher educational institutes. Figure- 2 depicts the proposed framework of the study.

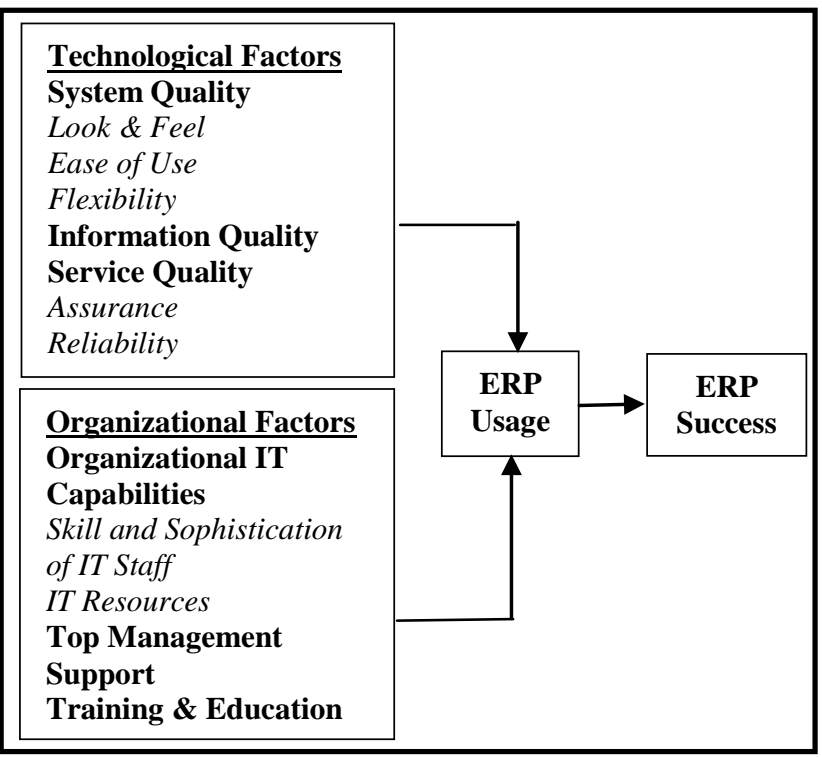

Figure-2: Proposed Research Framework

\section{SCALE DEVELOPMENT AND SAMPLE SIZE}

Exploratory study approach is used for this study. Quantitative and qualitative research approach is used to enhance the validity of findings. To test the research framework, survey based method was used. The unit of analysis of this study was the higher educational institutes. Study ensured that ERP users at all levels like faculty, officers, staff and IT personnel were contacted and included in the study. The above measure constructs are tested in the business environment and this is study is in the higher educational context. Therefore Before confirming above constructs for the measurement of ERP success, list of the identified constructs are sent to experts from different areas for their views. Experts' opinion and their views are collected through emails. Ten ERP experts from academia and industry reviewed the questionnaire. Questionnaire was re-designed and rewarded as per the suggestions of the experts which helped in increasing the accuracy and reduced the measurement error of survey instrument.

To collect data for the study random convenience sampling method is used. It is noted that the sample size should not be 
less than the number of items in the questionnaire [58]. The number of items for the variables was 50 . This indicate that the minimum sample size required for this study should be 50 . The desirable sample size would be equivalent to ten times of the number of paths to a construct in a model [59]. From the model it can be observed that, there are 11 paths from the independent variables to the dependent variable, thus, by Barclay et al. [59] suggestions, the required sample size was 110. From this it is concluded that the required sample size for the study should be between 50 and110. The total sample size of this study is 346 which is greater than the required range.

\section{DATA COLLECTION AND ANALYSIS}

437 Institutes were approached from pan India where ERP is implemented. Out of which 205 HEIs responded. To overcome the likelihood of having a bias in sample selection, data from almost 50 percent of the total population has been taken. By comparing the sample size of past studies it is found that sample size considered for this study is adequate. Past studies on measuring in ERP success were mostly done as a case based study [17]. Ifinedo [27] organization study have used comparable sample size to this study. The demographic profile of the responding institutes is presented in Table-2 and Table-3 below.

Table 2: Demographic profile of institutes/universities

\begin{tabular}{|l|r|r|r|}
\hline & Frequency & \multicolumn{1}{c|}{ Percent } & \multicolumn{1}{c|}{ Count } \\
\hline University & 135 & 39.0 & 81 \\
\hline Institute & 211 & 61.0 & 124 \\
\hline Total & $\mathbf{3 4 6}$ & $\mathbf{1 0 0 . 0}$ & $\mathbf{2 0 5}$ \\
\hline National & 88 & 25.4 & 41 \\
\hline State & 161 & 46.5 & 122 \\
\hline Private & 97 & 28.0 & 42 \\
\hline Total & $\mathbf{3 4 6}$ & $\mathbf{1 0 0 . 0}$ & $\mathbf{2 0 5}$ \\
\hline Technical & 143 & 41.3 & 73 \\
\hline Non-Technical & 122 & 35.3 & 87 \\
\hline Both & 81 & 23.5 & 45 \\
\hline Total & $\mathbf{3 4 6}$ & $\mathbf{1 0 0 . 0}$ & $\mathbf{2 0 5}$ \\
\hline In-Source & 58 & 16.8 & 25 \\
\hline Out Source & 288 & 83.2 & 180 \\
\hline Total & $\mathbf{3 4 6}$ & $\mathbf{1 0 0 . 0}$ & $\mathbf{2 0 5}$ \\
\hline
\end{tabular}

Table 3: Demographic profile of ERP users

\begin{tabular}{|l|r|r|}
\hline & \multicolumn{1}{|c|}{ Frequency } & \multicolumn{1}{|c|}{ Percent } \\
\hline Male & 269 & 77.7 \\
\hline Female & 77 & 22.3 \\
\hline Total & $\mathbf{3 4 6}$ & $\mathbf{1 0 0 . 0}$ \\
\hline Faculty & 112 & 32.4 \\
\hline IT-Personnel & 115 & 33.2 \\
\hline Officer & 67 & 19.4 \\
\hline Staff & 52 & 15.0 \\
\hline Total & $\mathbf{3 4 6}$ & $\mathbf{1 0 0 . 0}$ \\
\hline
\end{tabular}

To judge adequate sample size and institute type and institute category participated in the study, Chi-square (x2) test was used to compare the institute type and institute category. The results of the Chi-square tests $(\mathrm{p}<0.05)$ indicated that there were no significant differences along institute type and institute category. To control common method bias procedural method was followed. First, instrument's validity is enhanced by using clear and brief questions in questionnaire. Secondly, respondent's inhibition is reduced by giving them respondent's secrecy assurance. Third, Harmon one factor test was performed to test whether such biases are present in the study. The test result showed that most of the factors having eigenvalues larger than one are present in the data. As well, the one factor covariance is $37.55 \%$ which indicate that problem of common method variance is not present in the data.

\subsection{Reliability Analysis}

Cronbach's alpha was used to measure internal consistency. The results for mean, standard deviation and Cronbach's $\alpha$ shown in Table 4. Composite reliability is as same as the Cronbach's $\alpha$ and both can be inferred in the same way $[59,27]$. Each of the eleven measures had Cronbach's $\alpha$ and composite reliability exceeding the suggested value of 0.60 . As suggested by Fornell \& Larcker [60], convergent validity is adequate if value of Average Variance Expected (AVE) of each constructs in the model is greater than or equal to 0.50 .

Table 4 - Descriptive statistics of the variables

\begin{tabular}{|c|c|c|c|c|c|}
\hline Factors & Mean & $\begin{array}{c}\text { Std. } \\
\text { Deviation }\end{array}$ & $\begin{array}{c}\text { Cronba } \\
\text { ch's } \alpha\end{array}$ & AVE & $\begin{array}{c}\text { Composite } \\
\text { Reliability }\end{array}$ \\
\hline LnF & 4.06 & 0.64 & 0.61 & 0.57 & 0.79 \\
\hline EOU & 3.93 & 0.71 & 0.87 & 0.56 & 0.90 \\
\hline FX & 3.86 & 0.73 & 0.74 & 0.57 & 0.84 \\
\hline IQ & 3.89 & 0.59 & 0.78 & 0.53 & 0.85 \\
\hline REL & 3.97 & 0.65 & 0.78 & 0.60 & 0.86 \\
\hline ASSU & 4.07 & 0.66 & 0.73 & 0.57 & 0.84 \\
\hline SSITS & 3.95 & 0.82 & 0.79 & 0.71 & 0.88 \\
\hline ITR & 3.98 & 0.76 & 0.75 & 0.68 & 0.86 \\
\hline TMS & 3.97 & 0.71 & 0.89 & 0.61 & 0.92 \\
\hline TE & 3.99 & 0.70 & 0.74 & 0.66 & 0.86 \\
\hline EU & 3.97 & 0.64 & 0.81 & 0.52 & 0.87 \\
\hline
\end{tabular}

\subsection{Discriminant Validity}

The results of discriminant validity showed that there is no correlation between the constructs. The square root of AVE is greater than the correlation value of each construct. The value of AVE of all constructs is greater than 0.5. The composite reliability of all constructs is greater than the value of AVE (see Table 6). The value of AVEs is ranged from 0.52 to 0.71 . On the whole, results showed the variance shared between each construct and its items are distinct and unidimensional. Thus, the discriminant validity of the scales used for this study is acceptable.

\subsection{Confirmatory Factor Analysis (CFA)}

CFA was used to assess the fit of the measuring items for describing the behavior of the unobserved latent variables mentioned above. CFA was employed for examining construct validity of each scale by assessing how well the individual item measured the construct. Figure 3 indicate the structural equation model of the constructs technological factor, organizational factor and ERP usage. In this study, the method used was a maximum likelihood. The measurement model fits with the data was checked with Chi-square, CMIN/df, RMSEA, CFI, GFI, NFI, RMR, AGFI, TLI, RMSEA values [61]. All model fit indices of the model are satisfying the suggested values. Details are presented in Table 5. 
Table 5: Model fit indices

\begin{tabular}{|l|l|l|}
\hline Fit statistic & Recommended & Value \\
\hline Chi Sqaure & & 318.429 \\
\hline $\boldsymbol{x}^{\mathbf{2}}$ significance & $p<=0.05$ & $0.000^{\mathbf{a}}$ \\
\hline $\boldsymbol{x}^{\mathbf{2}} / \boldsymbol{d} \boldsymbol{f}$ & $<5.0$ & $3.317^{\mathbf{a}}$ \\
\hline GFI & $>=0.80$ & $0.89^{\mathbf{a}}$ \\
\hline
\end{tabular}

\begin{tabular}{|l|l|l|}
\hline AGFI & $>=0.80$ & $0.85^{\mathrm{a}}$ \\
\hline NFI & $>0.90$ & $0.91^{\mathrm{a}}$ \\
\hline CFI & $>0.90$ & $0.94^{\mathrm{a}}$ \\
\hline TLI & $>0.90$ & $0.92^{\mathrm{a}}$ \\
\hline RMSEA & $<0.10$ & $0.08^{\mathrm{a}}$ \\
\hline RMR & $<0.04$ & $0.02^{\mathrm{a}}$ \\
\hline
\end{tabular}

${ }^{\mathrm{a}}$ Satisfy the suggested value

Table 6: Fornell-Larcker Criteria - Inter Construct Correlations, AVE, and the square root of AVE.

\begin{tabular}{|l|c|c|c|c|c|c|c|c|c|c|c|c|}
\hline & AVE & LnF & EOU & FX & IQ & REL & ASSU & SSITS & ITR & TMS & TE & EU \\
\hline LnF & $\mathbf{0 . 5 7}$ & $\mathbf{0 . 7 5}$ & & & & & & & & & & \\
\hline EOU & $\mathbf{0 . 5 6}$ & 0.51 & $\mathbf{0 . 7 5}$ & & & & & & & & & \\
\hline FX & $\mathbf{0 . 5 7}$ & 0.45 & 0.59 & $\mathbf{0 . 7 5}$ & & & & & & & & \\
\hline IQ & $\mathbf{0 . 4 6}$ & 0.49 & 0.57 & 0.51 & $\mathbf{0 . 6 8}$ & & & & & & & \\
\hline REL & $\mathbf{0 . 6 0}$ & 0.37 & 0.48 & 0.46 & 0.49 & $\mathbf{0 . 7 7}$ & & & & & & \\
\hline ASSU & $\mathbf{0 . 5 7}$ & 0.38 & 0.43 & 0.43 & 0.48 & 0.49 & $\mathbf{0 . 7 5}$ & & & & & \\
\hline SSITS & $\mathbf{0 . 7 1}$ & 0.38 & 0.55 & 0.50 & 0.43 & 0.51 & 0.51 & $\mathbf{0 . 8 4}$ & & & & \\
\hline ITR & $\mathbf{0 . 6 8}$ & 0.32 & 0.46 & 0.43 & 0.36 & 0.52 & 0.45 & 0.65 & $\mathbf{0 . 8 2}$ & & & \\
\hline TMS & $\mathbf{0 . 6 1}$ & 0.39 & 0.46 & 0.42 & 0.41 & 0.49 & 0.46 & 0.50 & 0.52 & $\mathbf{0 . 7 8}$ & & \\
\hline TE & $\mathbf{0 . 6 6}$ & 0.34 & 0.44 & 0.45 & 0.38 & 0.43 & 0.36 & 0.47 & 0.40 & 0.49 & $\mathbf{0 . 8 1}$ & \\
\hline EU & $\mathbf{0 . 5 2}$ & 0.43 & 0.52 & 0.49 & 0.50 & 0.57 & 0.54 & 0.54 & 0.48 & 0.52 & 0.45 & $\mathbf{0 . 7 2}$ \\
\hline
\end{tabular}

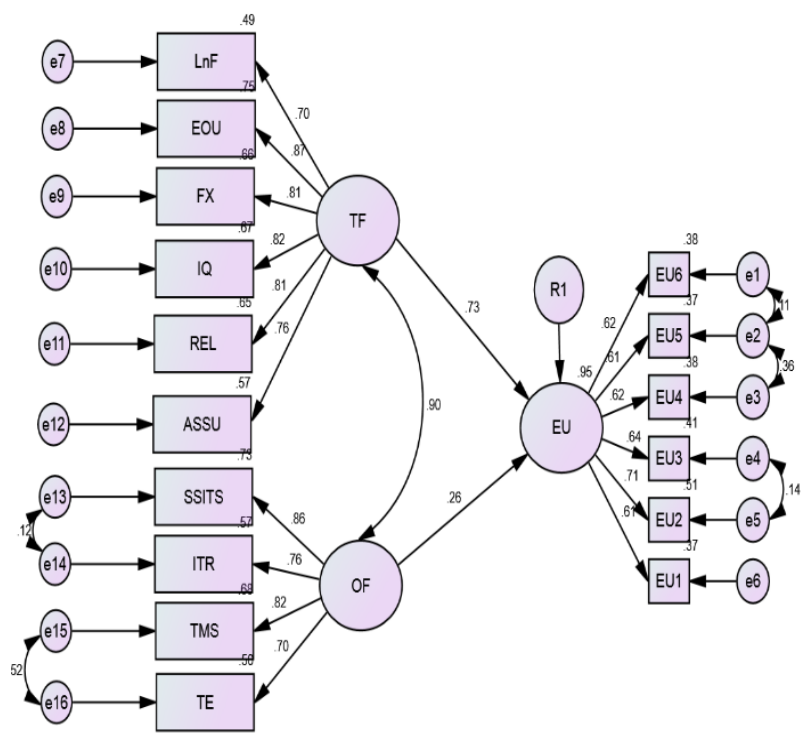

Figure 3- Structural Equation Model

\subsection{Correlation between Organizational IT capabilities and Top Management Support}

The main aim of the HEIs to implement ERP is to manage and streamline their processes than the profit making and competition advantage. Due to difference in objectives, work culture and processes of the HEIs and business, the usage of ERP is impacted by the different factors in both the environment. In business, the use of ERP is mandatory as their business processes are entangled into ERP software whereas in HEIs it is not possible to automate all processes into ERP software. Therefore use of ERP is only when required module is present in the ERP software and it requires motivation. In HE institutes, there are several issues at user level such as knowledge sharing, lack of trust, fear of loss of power, lack of social network. At the organizational level there is a lack of leadership, lack of appropriate reward system, and lack of sharing opportunities; and at the ERP software level there is an inappropriate technology systems, and lack of training on implanted system [62].

In this study correlation between Organizational IT capabilities and Top management support was also calculated. As these are the two most important factors for ERP success in HEIs. From Figure 4 it is observed that institute having high top management support showing high Organizational IT capabilities and vice-versa. There is a positive correlation and statistical significance between Organizational IT Capabilities and ERP usage $(\mathrm{r}=0.721, \mathrm{p}<0.05)$ and top management support and ERP usage $(\mathrm{r}=0.636, \mathrm{p}<0.05)$.

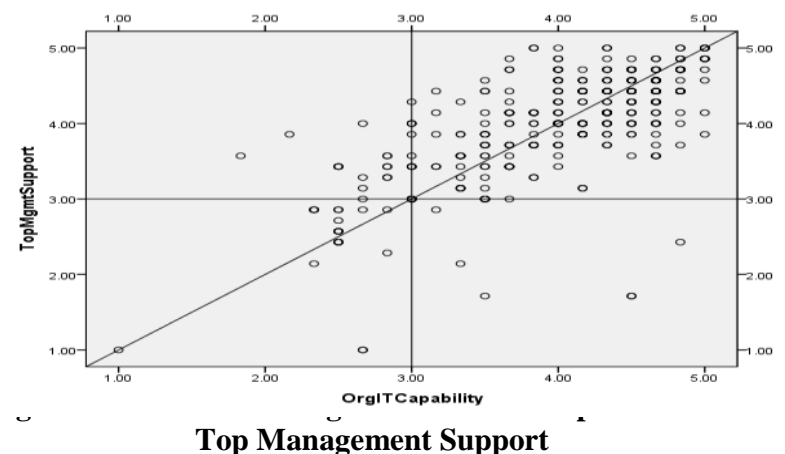

\section{CONCULSION}

Current literature suggest of the non-availability of extensive research on the measuring of ERP success in HE context. However, very limited study has been available on ERP systems in the higher education environment $[63,5,22,20]$. This study explores and analyzes the existing literature on ERP success and attempts to identify the factors which has the influence on ERP usage in higher education environment. The 
objective of this research is to empirically test the validity of identified factors for measuring ERP success in Indian higher education environment. In this study ERP technological factors and organizational factors are the independent variables. ERP quality is measured with three technological dimensions which are system quality, information quality and service quality. Organizational factors are top management support, organization IT capabilities and Training \& Education. ERP usage is a mediating variable and ERP success is a dependent variable. Result shows that the measures identified for measuring ERP success in Indian HE environment are appropriate. This study of ERP excludes the technical installation success of such systems. The focus of this study is on ERP usage at the general level i.e., ERP usage in technological and organizational context rather than differentiating ERP product between off-the shelf or in-house developed.

Adoption of ERP in Indian HEIs has lately accelerated and it is different from that in universities of other countries on aspects like IT infrastructure and IT resources, absence of IT exposure and knowledge of the administrative staff, organizational structure which is different from the business, vendor know-how in implementing ERP in HEIs, and implementation and post implementation support in the Indian IT market. For instance, many of the administrative staff in educational institutions are not exposed to computer usage, whereas introduction of ERP systems requires extensive training of the administrative staff [64]. Some of the challenges in Indian HE before ERP implementation is educating people of the HE about ERP, top management commitment, providing training facilities to users, involving right people during the ERP implementation which needs to be considered and addressed properly for successful implementation of ERP [7]. Inadequate fund for ERP implementation, lack of experience in IT and non-availability of resources influences the ERP implementation in developing countries $[65,20]$.

From Figure-4 it is observed that there is necessity of strategic action required to sustain ERP success in post implantation stage where top management support and organizational IT capabilities are low. IT capabilities can be enhanced by giving required training of ERP software to IT staff. Top management is required to take periodic review of implemented system and adopt a strategy to motivate people of the institute for making maximum usage of ERP. Second scenario where Top management support is high and IT capabilities are low. In this case, top management required to focus on improving the IT capabilities with the help of training and recruiting qualified and skilled professionals to manage ERP software. Third scenario where IT capabilities are high and top management support is low. In this case it is the responsibility of the IT staff to motivate the ERP users for making maximum use of ERP software and thereby increasing the dependency on ERP software. So that, top management will understand the benefits of ERP software and will take appropriate measures for ERP success. Fourth scenario where top management support and IT capabilities are high is the ideal scenario to increase ERP usage and create value from the implemented system.

Further, in the structural equation model shown in Figure 4, all the path loadings were found to be significant, with fair indices of model fit (see Table 6). Further, the ERP Success scale was divided into technological factors and organizational factors. In this, the technological factors was found to have 73 per cent effect on ERP usage whereas the organizational factors scale described 26 per cent effect on ERP usage. Thus, it may be concluded that the technological factors are more significant than the organizational factors for ERP usage in higher educational institutes.

Technological factor "Ease of Use" which is showing highest reliability (0.90) and highest path loading value (0.87). Many ERP system available in the market are the standardized package which are designed for any business to implement with minimum customization. The problem of higher education is that their processes are not similar like business and these generic systems are typically not designed with the unique need of higher educational institutes. Too much of customization increases the complexity of the software and project cost which in turn either abandon the project or delay the project. Higher educational institutes if implement standard ERP software available in the market which cannot be easily configured and fulfilling the need of higher educational institutes, the result can be unsuccessful. These standard packages are very difficult for the institute employee to use. Therefore, some end either with limited use or ignoring it completely and following their old traditional method. While transitioning toward implementing ERP system, higher educational institutes should considered following points. This will help in smooth implementation of ERP system and make maximum usage of ERP for the benefit of the institute. Higher educational institutes should consider following points while implementing ERP in the institutes.

\subsection{Ease of Use}

Faculty, officers and staff of the higher educational institutes are always busy enough in their time bound activities. Considering the downscaling of employee due to recent budget cuts, ERP systems implanted in higher educational institutes should be easy to use which requires extensive training to the user to operate. ERP should be customized from the beginning as per the institute unique need. ERP system should be flexible enough to accommodate any changes as higher educational institutes are subject to frequent policy changes. ERP system should be designed by keeping characteristics of users of the higher educational institutes in mind so that users will adopt the system easily and the benefits of using the system be worth the cost and time associated with installing and learning it.

\subsection{Top Management Support}

The composite reliability of the top Management support was 0.92 which is showing highest reliability amongst the organizational factor. Top management support is one of the most important factor and major influence agent of ERP success $[7,66,67,68,69,70]$. Top management needs to constantly monitor the progress of the project throughout all phases [53]. Top management is the main change factor responsible for looking and detecting factors in the organization which will cause people to change their behavior towards ERP [71].

\subsection{IT capabilities/resources to support ERP system}

IT capabilities enable organizations to deliver IT services to an enterprise. They include ability to continually improve and automate organizational processes, and the ability to manage the IT infrastructure of the organization effectively. Higher educational institutes are not IT driven organizations. They are facing the issues like lack of trained IT staff, connectivity 
issues and shortage of funds. HEIs are having the department with limited IT staff available for managing IT resources and helping the institute to automate the academic processes. Therefore it is required to assess the capabilities of the available IT people, their knowledge, Skill and education while measuring ERP success [72]. This study is among the first of its kind to attempt to combine the effects of selected IT-related assets and resources on ERP success in higher education environment. Organizational IT capabilities is measured on two dimensions which are Skill and sophistication of IT staff and IT resources.

\section{IMPLICATION OF THE STUDY}

The nature of HEI that are different from other organizations $[73,5]$.

'Colleges and universities are organized along the lines of academic and professional disciplines, grouped into larger units such as a college of arts and sciences or a school of engineering, as well as into smaller subunits such as a department of history or an institute of biotechnology research [74]'.

The parallel structure divided into highly specialized academic units in universities makes decision-making processes different from those of corporations, which have formal and hierarchical communication structure.

Which is more crucial for an optimum ERP success in higher education environment? Is it the technological factors consists of system quality, information quality, service quality or organization factors consist of top management support, organization IT capabilities and training and education? Whether these two factors influences ERP usage? Answers to some of the foregoing questions will be useful for academicians and practitioner. This study makes key contribution to the theory and practice related to usage of ERP and its success in higher education environment. Nowadays HE is gradually growing like a business and is realizing the need of investing into ERP system to manage their resources effectively and efficiently. Many of the higher education institutes have started implementing ERP system but ERP usage is not sustained over a period which affects the ERP success. This study attempts to identify the reason by examining the antecedents of ERP system success.

This study presents the potential to contribute to theory development with regard to measure ERP success in the under-researched context of Indian HE. This study should be of practical importance to managers and executives of the higher education institutes who grapple with the challenges of sustaining the ERP usage and managing their resources efficiently with the help of ERP system. Thus, prior to deployment, it may be more substantial for higher education institutes to consider how well the ERP software meant for the educational institute captures critical organization processes, user interface and information quality. Furthermore the higher educational institutes will not only focus on technical aspects of the ERP software for ERP's success but will simultaneously focus on organizational aspects such as continuing top management support at ERP post implementation phase and strengthening the organizational IT capabilities for smooth functioning of ERP at HE.

\section{LIMITATIONS AND FUTURE DIRECTION}

Data required for this study was collected from higher educational institutes of India; therefore, the outcome of this study cannot be generalized and it may not be applicable to other sectors or countries. The conceptual model developed in the study might be used to examine the ERP success in the context of other researches. Although this study makes a number of contributions, like other research studies, it suffers from some limitations as well. First, the study is based on the limited number of variables which influences ERP usage in higher educational institutes. The conceptual framework presented a review of the existing available literature in ERP in HE environment, there was a limited research on the impact of ERP usage in HEIs of India. This postured difficulties in comparing the finding of the study with other similar studies or from a similar context. Also, there was lot inhibition amongst the respondents to participate in the study as well getting availability and readiness to participate in the study. As the participation of respondents was voluntary, therefore it was not possible to include every stakeholder of the institute in the research study.

\section{REFERENCES}

[1] Mukti, S. K. Tripathi, P. and Rawani, A. M. A Framework for Investigating the ERP System Quality from Users Point of View in Indian Industries, Journal of Economics, Business and Management, 1(4), 2013.

[2] Ahed Abugabah Louis Sansogni Osama Alfarraj. Evaluating the impact of ERP systems in higher education. The International Journal of Information and Learning Technology, 32(1): 45 - 64, 2015.

[3] Elmeziane, K. and Elmeziane, M. Enterprise resources planning systems implementation success in China. Business and Management Review, 12(1): 1-9, 2012.

[4] Kallunki, J. P. Laitinen, E. K. and Silvola, H. Impact of enterprise resource planning systems on management control systems and firm performance. International Journal of Accounting Information Systems, 12(1): 2039,2011 .

[5] Rabaa'i, Ahmad A., Bandara, Wasana, and Gable, Guy. ERP systems in the higher education sector: a descriptive study. In Proceedings of the 20th Australasian Conference on Information Systems, Monash University: Caulfield Campus, Melbourne, 456-470, 2009.

[6] Karande, S. H. Jain, V. K. \& Ghatule, A. P. ERP implementation: critical success factors for Indian Universities and higher educational institutions. Pragyaan Journal of Information Technology, 10(2): 24$29,2012$.

[7] Thankur, A. Enterprise Resource Planning (ERP) Implementation in Technical Educational Institutes: Prospects and Challenges. International Journal of Multifaceted and Multilingual Studies, 3(2), 2016.

[8] Ghuman, K. \& Chaudhary, S. Incorporation of ERP in Educational Institutions: An Empirical Study. International Conference on Technology and Business Management, 2012.

[9] Staehr, L. Shanks, G. and Seddon, P., B. An Explanatory Framework for Achieving Business Benefits from ERP system. Journal of the Association for Information Systems, 13(6), 2012.

[10] Abugabah, A. and Sansogni, L. Enterprise Resource 
Planning (ERP) System in Higher Education: A Literature Review and Implications. International Journal of Human and Social Sciences, 5(6), 2010

[11] Al-Mashari, M. Enterprise resource planning (ERP) systems: a research agenda. Industrial Management and Data Systems, 103(1): 165-70, 2002.

[12] Saeed Jahanyan Adel Azar Hasan Danaee Fard. Utilising multi-aspectual understanding as a framework for ERP success evaluation. Journal of Enterprise Information Management, 25(5): 479-504, 2012.

[13] Delone, W., H. \& McLean, E., R. The DeLone and McLean Model of Information Systems Success: A TenYear Update. Journal of Management Information Systems, 19(4): 9-30, 2003.

[14] Goodhue, D. L. and Thompson, R. L. Task-Technology Fit and Individual Performance. MIS Quarterly, 19(2): 213-236, 1995.

[15] Sabherwal, R. Jeyaraj, A. and Chowa, C. Information System Success: Individual and Organizational Determinants. Management Science, 52(12): 1849-1864, 2006.

[16] Sedera, Darshana and Gable, Guy. A Factor and Structural Equation Analysis of the Enterprise Systems Success Measurement Model. ICIS 2004 Proceedings, Paper 36, 2004

[17] Althonayan, M. and Papazafeiropoulou, A. Evaluating the Performance of ERP Systems in Saudi Arabian Higher Education: A Stakeholders' Perspective. Proceedings of the European Conference on Information Management; 473, 2011.

[18] Fryling, M. Investigating the Effect of Customization on Rework in a Higher Education Enterprise Resource Planning (ERP) Post-Implementation Environment: A System Dynamics Approach. Journal of Information Technology Case and Application Research, 17(1), 2015.

[19] Kevin, P. Gallagher Vickie Coleman Gallagher. Organizing for post-implementation ERP. Journal of Enterprise Information Management, 25(2): 170 - 185, 2012.

[20] Nizamani, S. Khoumbati, K. Ismaili, I. A. and Nizamani, S. A Conceptual Framework for ERP Evaluation in Universities of Pakistan. Sindh University Research Journal (Science Series), 45(3): 467-475, 2014.

[21] Pei-Fang, H. Hsiuja, R. Y. and Jung-Ching, C. Assessing ERP post-implementation success at the individual level; Revising the role of service quality. Information \& Management, Inf. Manage. http://dx.doi.org/10.1016/j.im.2015.06.009

(2015),

[22] ALdayel, A. Aldayel, M. and Al-Mudimigh, A. The Critical Success Factors of ERP implementation in Higher Education in Saudi Arabia: A Case Study. Journal of Information Technology \& Economic Development, 2(2): 1-16, 2011.

[23] Goel, S., Kiran, R. and Garg, D. A framework of efficient enterprise resource planning (ERP) implementation in technical educational institutions. African Journal of Business Management, 5(34): 1319713204, 2011.
[24] Wixom, B. H. and Todd, P., A. A Theoretical Integration of User Satisfaction and Technology Acceptance. Information Systems Research, 16(1): 85-102, 2005.

[25] Ifinedo, P. An empirical study of ERP success evaluations by business and IT managers. Information Management \& Computer Security, 15(4): 270-282, 2007.

[26] Chung, BooYoung, Mirosław J. Skibniewski, and Young Hoon Kwak. Developing ERP systems success model for the construction industry. Journal of Construction Engineering and Management 135.3 (2009): 207-216, 2009.

[27] Ifinedo, P. Udo, G. and Ifinedo, A. Organization Culture and IT Resources Impacts on ERP System Success: An Empirical Investigation. Int. J. Business and System Research, 49(2): 131-147, 2010

[28] Abdel, N. H. An Integrated Success Model for Evaluating Information System in Public Sectors. Journal of Emerging Trends in Computing and Information Sciences, 3(6), 814-825, 2012.

[29] Rajan, C. A., Baral, R. Adoption of ERP system: An empirical study of factors influencing the usage of ERP and its impact on end user. IIMB Management Review, 27: 105-117, 2015.

[30] Seddon, and Peter B. (1997). A respecification and extension of the DeLone and McLean model of IS success. Information systems research, 8(3): 240-253, 1997.

[31] Bologa, R. Vologa, A. R. and Sabau, G. (2009), Success Factors of Higher Education ERPs, International Conference on Computer Technology and Development, IEEE, 2009.

[32] Al-Shamlan, H. M. and Al-Mudimigh, A. S. The Chang Management Strategies and Processes for Successful ERP Implementation: A Case Study of MADAR. International Journal of Computer Science, 8: 431-435, 2011.

[33] Ragowsky, A. Somers, T. M. and Adams, D. A. Assessing the Value Provided by ERP Applications through Organizational Activities, Communications of the Association for Information Systems, 16: 381-406, 2005.

[34] Zaied, A. N. H. (2012). An Integrated Success Model for Evaluating Information System in Public Sectors. Journal of Emerging Trends in Computing and Information Sciences, 3(6): 814-825, 2012.

[35] Petter, S. DeLone, W. and McLean, E. Measuring Information Systems Success: Models, Dimensions, Measures, and Interrelationships. European Journal of Information Systems, 17: 236-263, 2008.

[36] Ajzen, I. and Fishbein, M. Understanding attitudes and predicting social behavior. Englewood Cliffs, NJ: Prentice-Hall, 1980.

[37] Venkatesh, V. and Davis, F. D. (2000). Theoretical acceptance extension model: field four studies of the technology longitudinal. Management Science, 46(2): 186-204, 2000 
[38] Almajali, D. A. Masa'deh, R. \& Tarhini, A. (2015). Antecedents of ERP systems Implementation Success; A Study on Jordanian Healthcare Sector. Journal of Enterprise Technology Management, 21(4): 549 - 565, 2015.

[39] Gable, G. Sedera, D. and Chan, T. Reconceptualizing information system success: The IS-impact measurement model. Journal of the Association for Information Systems, 9(7): 377-408, 2008.

[40] Sylvestre, U. and Louis, R. Essential Characteristics of an ERP System: Conceptualization and Operationalization. In Sixth International Conference on Enterprise Information Systems, Porto, Portugal, 2004.

[41] Lee, Y. W., Strong, D. M., Kahn, B. K. and Andwang, R. AIMQ: A methodology for information Quality Assessment. Information Management, 40(2): 133-460, 2002.

[42] Leyland, F. P. Richard, T. and Bruce, K. Service Quality: A Measure of Information Systems Effectiveness. MIS Quarterly, 19(2): 173-187, 1995.

[43] Jiang, J. J. Gary, K. and Christopher L. Measuring information system service quality: SERVQUAL from the other side. Mis Quarterly, 145-166, 2002.

[44] Parasuraman, A. Berry, L. L. and Zeithaml, V., A. SERVQUAL: A multiple-item scale for measuring consumer perceptions of service. Journal of Retailing, 64(1): 12-40, 1988.

[45] Gorla, N. Somers, T. N. and Wong, B. Organizational Impact of System Quality, Information Quality and Service Quality. Journal of Strategic Information Systems, 19: 207-228, 2010.

[46] Ratkevičius, D., Ratkevičius, C., and Skyrius, R. ERP selection criteria: Theoretical and practical views. Ekonomika, 91(2), 2012.

[47] Lester, D. and Tran, T. Information capabilities: suggestion for SME growth, Journal of Behavioral and Applied Management, 10(1): 72-89, 2008.

[48] Ainin, S. Kamarulzaman, Y. and Farinda, A. G. Assessment of Technological Competencies on Professional Service Firms Business Performance. World Academy of Science, Engineering and Technology, 4, 2010.

[49] Kevin P. Gallagher, James L. "Jamey" Worrell, Robert M. Mason. The negotiation and selection of horizontal mechanisms to support post-implementation ERP organizations. Information Technology \& People, 25(1): $4-30,2012$.

[50] Ein-Dor, P. \& Segev, E. Organizational context and the success of management information systems. Management Science, 24(10): 1064-1077, 1978.

[51] Noaman, A. Y. and Ahmed, F. F. ERP system Functionalities in Higher Education. Procedia Computer Science 65: 385-395, 2015.

[52] Ifinedo, P. Impacts of business vision, top management support, and external expertise on ERP success. Business Process Management Journal, 14(4): 551-568, 2008.

[53] Kronbichler, S. A. Ostermann, H. and Staudinger, R. A
Review of Critical Success Factors for ERP-Projects. The Open Information Systems Journal, 3: 14-25, 2009.

[54] Hsu, J. Huang, C. and Hsu, P. The Exploration of Top Management Support to the ERP Project then Influence user Satisfaction - use the information, system, service quality as the moderators. In Proceedings of the Fourth Workshop on Knowledge Economy and Electronic Commerce, 2005.

[55] Abdel, M., A. Change Management Strategies for Successful ERP Implementation. Business Process Management Journal, 7:266 - 275, 2001.

[56] Jahanyan. S. Azar, A. and Fard, H. D. Utilising multiaspectual understanding as a framework for ERP success evaluation A case study. Journal of Enterprise Information Management, 25(5): 479-504, 2012.

[57] Jain, V. What Makes ERP Systems to Deliver? Impact of Post-Implementation Capabilities on ERP Value, In 18th European Conference on Information Systems (ECIS), ISBN 978-0-620-47172-5, 2010.

[58] MacCallum, R. C. Browne, M. W. and Cai,. Testing differences between nested covariance structure models: Power analysis and null hypotheses. Psychological Methods, 11(1): 19-35, 2006.

[59] Barclay, D. Thompson, R. and Higgins, C. The partial least square approach to casual modeling: Personal computer adoption and use as an illustration. Technology Studies: Specials Issue on Research Methodology, 2(2): 285-324, 1995.

[60] Fornell, C. and Larcker, D. F. Evaluating structural equations models with unobservable variables and measurement error. Journal of Marketing Research, 8(1): 39-50, 1981.

[61] Hair, J. Black, W. Babin, B. and Anderson, R. E. Multivariate data analysis. (7th ed. Upper Saddle River, NJ: Pearson Prentice Hall, 2010.

[62] Fatma Ozman. The capabilities of the educational organizations in making use of tacit knowledge. Procedia Social and Behavioral Sciences, 9: 1860-1865, 2010.

[63] Okunoye, Adekunle, Mark Frolick, and Elaine Crable. Stakeholder influence and ERP implementation in higher education. Journal of Information Technology Case and Application Research, 10(3): 9-38, 2008.

[64] Bhat, J. M. Shroff, B. and Bandi, R,. K. User Perceptions, Motivations and implications on ERP Usage: An Indian Higher Education Context. CONFENIS 2012, LNBIP 139: 90-105, 2013.

[65] Upadhyay, P. and Dan, P. K. User's perspective of factor (s) influencing for ERP implementation in small and medium enterprises in India. International Journal of Electronic Customer Relationship Management, 4(1): 77 86, 2010.

[66] Elbanna, A. Top management support in multiple-project environments: an in-practice view. European Journal of Information Systems, 1-17, 2012.

[67] Seo, G. Challenges in Implementing Enterprise Resource Planning (ERP) system in Large Organizations: Similarities and Differences between Corporate and 
University Environment. Master's thesis, Massachusetts Institute of Technology, Cambridge, 2013.

[68] Andrew Lawrence Norton Yvette May Coulson-Thomas Colin Joseph Coulson-Thomas Colin Ashurst. Ensuring benefits realisation from ERP II: the CSF phasing model. Journal of Enterprise Information Management, 26(3): $218-234,2013$

[69] Kale, P. T. Banwait, S. S. and Laroiya, S. C. Performance evaluation of ERP implementation in Indian SMEs. Journal of Manufacturing Technology Management, 21(6): 758 - 780, 2010.

[70] Madhavi Latha Nandi Ajith Kumar. Centralization and the success of ERP implementation. Journal of Enterprise Information Management, 29(5): 728-750, 2016.

[71] Thomas, N. M. \& Ziaul, H. Realigning Top
Management's Strategic Change Actions for ERP Implementation: How Specializing on Just Cultural and Environmental Contextual Factors Could Improve Success. Journal of Change Management, 7(2): 121-142, 2007.

[72] Soja, P. Difficulties in enterprise system implementation in emerging economies: Insights from an exploratory field study in Poland. Information Technology for Development, 14(1): 31-51, 2008.

[73] Pollock, N. James, C. ERP systems and the university as a "unique" organization. Information Technology \& People, 17(1): 31-52, 2004.

[74] Duderstadt, J. J. Atkins, D. E. and Van Houweling, D. E. Higher education in the digital age: Technology issues and strategies for American colleges and universities. Praeger Pub Text, 2002. 